\title{
A study of zinc borne waste water treatment with dispersion supported liquid membrane
}

\author{
Shibao $\mathrm{Lu}^{a, *}$, Liang Pei ${ }^{b}$ \\ a School of Public Administration, Zhejiang University of Finance and Economics, Hang Zhou 310018, China \\ ${ }^{\mathrm{b}}$ Key Laboratory of Water Cycle and Related Land Surface Processes, Institute of Geographic Sciences and Natural \\ Resources Research, Chinese Academy of Sciences, Beijing 100101, China
}

\section{A R T I C L E I N F O}

Article history:

Received 30 March 2016

Accepted 3 May 2016

Available online 17 June 2016

Keywords:

Liquid membrane

Dispersion supported liquid mem-

brane

2-ethyl hexyl phosphonic aeid-

mono-2-ethyl hexyl ester waste

water treatment

$\mathrm{Pb}$ (II)

\begin{abstract}
A B S T R A C T
This paper based on a theoretical study of the supported liquid membrane separation technology, explores the appropriate liquid membrane separation system, makes a study on the $\mathrm{Pb}$ (II) transmission behavior in the PC-88A-kerosene- $\mathrm{HCl}$ dispersion supported liquid membrane system and reviews influence of the feed liquid $\mathrm{pH}$ value, volume ratio between the membrane liquid and analytic agent, HCI concentration during analytic phase and initial $\mathrm{Pb}$ (II) transmission concentration. The results show that the migration of $\mathrm{Pb}$ (II) is well completed for 190 min with the migration rate being up to $95 \%$ on the premise that the feed liquid $\mathrm{pH}$ is equal to $6.0, \mathrm{~Pb}$ (II) initial concentration of $3.0 \times 10^{-3} \mathrm{~mol} / \mathrm{L}, \mathrm{HCl}$ concentration during the stripped and dispersed phase is $4.0 \mathrm{~mol} / \mathrm{L}$, volume ratio between the stripped liquid and organic phase is $40: 160$ and that of the conventional supported liquid membrane is only $72.4 \%$. The dispersion supported liquid membrane is characterized by higher transmission efficiency, stable membrane system and long membrane service life. The procedure has provided accurate results with zinc borne waste water treatment.
\end{abstract}

(C) 2016 Hydrogen Energy Publications LLC. Published by Elsevier Ltd. All rights reserved.

\section{Introduction}

Waste water in industry, daily life waste water and various waste waters in mining contain numerous heavy metals which should lead to food chain biological enrichment and cause serious threats to creatures and human health [1-3]. A heavy metal is a trace element which is indispensable to the human body health with its high content should bring serious consequences and the lead contamination is primarily due to waste water and garbage from mining, smelting, rubber production, dyestuff, printing, ceramics, lead glass, soldering, cables and lead pipes [4-6]. Lead shall be released to environment in production and operation process, and enter into the human body in a direct or indirect way, thus resulting in serious health problems such as stomachache, headache, tremor and neuro-dysphoria [7]. Given a low concentration, the chronic lead poisoning shall primarily affect the brain and nervous system. The lead borne waste water treatment method includes methods such as chemical precipitation, ion exchange, liquid-membrane, biological adsorption, electrolytic and so forth.

In order to minimize the heavy metals' serious influence on the ecological system, people have been in pursuit of new technology for the treatment of waste water contaminated by such metals. Pei and Yao [8] analyzes the zinc ion

\footnotetext{
* Corresponding author.

E-mail address: lu5111284@aliyun.com (S. Lu).
} 
transmission model in the PC-88A-kerosene supported liquid membrane system. Given different experimental conditions, more experiments have been carried out to predict the zinc transmission extent in a supported liquid membrane system. Bhattacharyya and Mohapatra [9] reports the trivalent chrome transmission in the liquid membrane system taking the di-phosphoric acid (2-ethyl hexyl) as carrier. Zhao and Shen [10] analyzes the bivalent and trivalent metal ion transmission behavior in the optional migration carried out in a supported liquid membrane, thereby taking a new type of organic phosphoric acid as carrier; the analysis results show that various adopted extraction agents will properly separate the mixed ions $\mathrm{Cu}$ (I), Co (II), Ni (II), Pb (II), Fe (III) and Cd (II). Pei and Yao [11] analyzes the silver and mercury transmission and separation in a generally improved and supported liquid membrane system with two-membrane and three-chamber system established to achieve a rapid silver and mercury ions separation. Artur and Marcelo [12] analyzes the cobalt ion solvent extraction adopting Cyanex272 as extraction agent and its migration by the supported liquid membrane focusing on discussion about the transmission flux in the liquid and the equilibrium constant in solvent extraction to obtain optimum experimental condition based on the liquid phase $\mathrm{pH}$, carrier Cyanex272 concentration, Co (II) concentration in liquid phase and the stripping agent acidity influence analysis. Hamed and Amirmostafa [13] analyzes zinc ion transmission model in the P C-88A-kerosene supported liquid membrane system with more experiments made to predict the zinc transmission extent in the supported liquid membrane system given experimental conditions together with the stirring rate, carrier concentration and temperature influence on the surveyed metal ion transmission.

The Supported Liquid Membrane (SLM) separation technology requires much attention due to its advantages comprising less energy consumption, low cost, favorable selectivity and banned secondary pollution. However, SLM separation technology has not been applied to industrialization, the reason for which is that transmission process shall make membrane phase diminish to nothing and bring about a declined separation performance and a reduced service life. The dispersion supported liquid membrane technology avoids the membrane phase disadvantage, thereby being liable to diminish to nothing in the supported liquid membrane. It is especially applicable to metal ion's low concentration enrichment and separation. The 2-ethylhexyl phosphoric acid - mono-2-ethylhexyl $\left(\mathrm{P}_{507}\right)$ is the metal ion extraction agent which is characterized by an excellent extraction property, small water solubility and has no poison.

The dispersion Supported Liquid Membrane (DSLM) technology presented in this paper is new and is developed based on SLM $[14,15]$. with the liquid membrane added to the analytical phase to constitute a dispersion system which is effectively capable of solving the membrane phase's petering out problem in SLM.I It is especially applicable to the low concentration metal ion enrichment and separation A study on the $\mathrm{Pb}$ (II) liquid membrane separation has been conducted, but there is still a lack of $\mathrm{Pb}$ (II) transmission DSLM technology report. The 2-ethylhexyl phosphoric acid - mono2-ethylhexyl ester (PC-88A) is a metal ion extraction agent which is characterized by an excellent extraction property, small water solubility and has no poison. This paper takes $\mathrm{P}_{507}$ as a flow carrier for the liquid membrane and selects PVDF as a support, kerosene as a membrane solvent to analyze the $\mathrm{Pb}$ (II) transmission process in the dispersion supported liquid membrane system composed of organic phosphoric acid-kerosene- $\mathrm{HCl}$ to discuss various factors and mechanisms which influence on its transmission so as to provide a theoretic foundation for effective $\mathrm{Pb}$ (II) borne waste water control.

\section{Experimental part}

\section{Instruments and reagents}

UV-1200 type spectrophotometer (Shanghai Huipuda Instrument Plant);

JJ-1 type precision and timing motor stirrer (Danyangmen Quartz Glass Plant in Jintan);

$\mathrm{P}_{507}$ :product name PC-88A, from Oba Chemical Industry Company in Japan;

$\mathrm{PbSO}_{4}, \mathrm{NH}_{3} \cdot \mathrm{H}_{2} \mathrm{O}, \mathrm{NH}_{4} \mathrm{Cl}, \mathrm{HAc}$ and $\mathrm{NaAc}$ are analytically pure; water for experiment is deionized.

The self-made dispersion supported liquid membrane migration pool comprises liquid, analytical pools and a support. The liquid and analytical pools are $200 \mathrm{~mL}$ in volume respectively, equipped with adjustable speed motor stirrer; the support is PVDF, and with $18 \mathrm{~cm}^{2}$ effective area.

\section{Experimental method}

The experiment process is performed as follows:

- PVDF is immersed in the membrane solution for a given time for adsorption;

- Take it out to volatilize the membrane solvent;

- Fix it to the migration pool;

- Add the prepared sample feed liquid and the membrane solution to feed liquid and analytical pools respectively;

- Start the stirrers in the fed liquid and analytical pools;

- Add appropriate $\mathrm{HCl}$ to the analytical pool and start timing to sample for analysis at different appropriate intervals.

$\mathrm{Pb}$ (II) concentration shall be determined by the spectrophotometric method.

\section{Experiment principle}

The metal ion reaction and migration processes in dispersion supported liquid membrane system are approximately composed of the following steps:

(1) Metal ion in feed liquid phase must pass through water dispersion layer between the feed liquid and membrane phases.

(2) The $\left(\mathrm{Pb}^{2+}\right)$ metal ion and carrier (HR), at interface between water-membrane phases, must have the following coordination reactions: 
$\mathrm{M}_{\mathrm{f}}^{2+}+\frac{\mathrm{m}+\mathrm{n}}{2}(\mathrm{HR})_{2, \text { org }} \underset{\mathrm{K}_{-1}}{\stackrel{\mathrm{K}_{1}}{\rightleftarrows}} \mathrm{MR}_{n} \cdot \mathrm{mHR}_{(\text {org })}+n \mathrm{H}_{f}^{+}$

where the subscripts: " $\mathrm{f}$ " indicates the water phase and "org" the membrane phase respectively. $\mathrm{M}_{\mathrm{f}}^{2+}$ is the divalent metal ion and $(\mathrm{HR})_{2}$ the extraction agent which exists in the form of a dimer in non-polar oil.

(3) The metal ion and carrier complex generated in the previous step is diffused in the membrane phase.

(4) The metal ion and carrier complex also diffuses into analytical phase and react with the stripping agent:

$\mathrm{MRn} \cdot \mathrm{mHR}_{\text {(org) }}+\mathrm{nH}_{\mathrm{s}}+\underset{\mathrm{K}_{-2}}{\stackrel{\mathrm{K}_{2}}{\rightleftarrows}} \mathrm{M}_{\mathrm{s}}^{2+}+\frac{m+n}{2}(\mathrm{HR})_{2, \text { org }}$

where the right subscript S stands for the stripping dispersion phase.

(5) The carrier shall return to the interface between the feed liquid and membrane phases.

Suppose that the above reactions are of first order, adopt $K_{1}, K_{-1}, K_{2}$ and $K_{-2}$ to represent the rate constant for forward and backward reactions in the extraction and stripping reactions respectively. The same supposition given in document [16-18] is referred to; which means that you have to use a linear concentration gradient, the concentration of charged species into the supported liquid membrane with low dielectric constant is to be ignored, and the permeated metallic substance concentration is lower. Therefore, proceed with the chemical reaction and stable state on continuous interface so as to derive new equation to describe the metal ion's permeability coefficient in the dispersion supported liquid membrane $[19,20]$.

$P_{c}=\frac{K_{d}}{K_{d} D_{f}^{-1}+D_{0}^{-1}+\frac{1}{K_{2}} \frac{V_{s}}{V_{0}}}$

where $K_{d}$ indicates the feed liquid phase metal ion distribution ratio, $D_{f}$ the metal ion dispersion coefficient, $D_{0}$ the membrane phase thickness, $V_{0}$ the membrane phase volume and $V_{s}$ the stripping phase volume.

It is obtained from the definition of rate constant and Equations (2)-(1) that

$\mathrm{K}_{1}=\frac{\left[\mathrm{H}^{+}\right]^{n}\left[\mathrm{MR}_{n} \cdot m \mathrm{HR}\right]}{\left[\mathrm{M}^{2+}\right]\left[(\mathrm{HR})_{2}\right]^{\frac{m+n}{2}}}=\frac{\mathrm{K}_{d} \cdot\left[\mathrm{H}^{+}\right]^{n}}{\left[(\mathrm{HR})_{2}\right]^{\frac{m+n}{2}}}$

and from Simultaneous Equations (2)-(3) and (2)-(4), it is obtained that

$\frac{1}{P_{c}}=D_{f}^{-1}+\left(D_{0}^{-1}+\frac{V_{s}}{K_{2} V_{0}}\right) \frac{\left[\mathrm{H}^{+}\right]^{n}}{\left[(\mathrm{HR})_{2}\right]^{\frac{m+n}{2}}}$

It is obvious that given a carrier concentration condition, 1/ $P_{C}$ has a linear relationship with $\left[\mathrm{H}^{+}\right]^{\mathrm{n}}$ and the analytic reaction's dispersion coefficient and rate constant are obtained by using the straight slope analysis method [21,22] Fig. 1.
By next, the metal ion mass transfer flux is obtained through the determination of the metal ion's time dependent concentration change rate $d c_{f} / d_{t}$ in the feed liquid phase. It is given by the following relation:

$J=-\frac{V_{f}}{A}\left(\frac{d c_{f}}{d_{t}}\right)=P_{c} \cdot c_{f}$

where $V_{f}$ denotes the feed liquid phase volume, $A$ is the membrane's effective area, and $c_{f}$ is the substance migrates concentration in feed liquid phase.

Integrating the Equation (6) you find:

$\ln \frac{C_{f(t)}}{C_{f(0)}}=-\frac{A}{V_{f}} P_{c} \cdot t$

where $c_{f(t)}$ and $c_{f(0)}$ are the metal ion concentrations in initial feed liquid phase at the time $t$ respectively. The metal ion in different conditions shall be determined to make a diagram 1 based on $\ln \left(c_{t} / c_{0}\right)$ to $t$ and analyze the extent of various factors' influence on the migration rate according to straight slope.

\section{Results and discussion}

Volume ratio influence between the membrane solution and $\mathrm{HCl}$ on $\mathrm{Pb}$ (II) transmission

The feed liquid phase $\mathrm{pH}$ is $6.0, \mathrm{~Pb}$ (II) initial concentration of $3.0 \times 10^{-4} \mathrm{~mol} / \mathrm{L}$, and $\mathrm{HCl}$ concentration of $3.0 \mathrm{~mol} / \mathrm{L}$ are selected for the experiment. The volume ratio influence between the stripping liquid and membrane solvent is represented by $20: 180,30: 170,40: 160,50: 150,60: 140$ on the $\mathrm{Pb}$ (II) migration. The experiment results are as shown in Fig. 2.

The experiment results show that when volume ratio exists between the stripping agent and membrane solvent, $\mathrm{Pb}$ (II) migration is favorable. This is the reason for which when the stripping agent $\mathrm{HCl}$ in the dispersion supported liquid membrane system is uniformly dispersed into membrane solution, the volume ratio between the membrane solution and $\mathrm{HCl}$ will have an immediate influence on the $\mathrm{Pb}$ (II) migration and

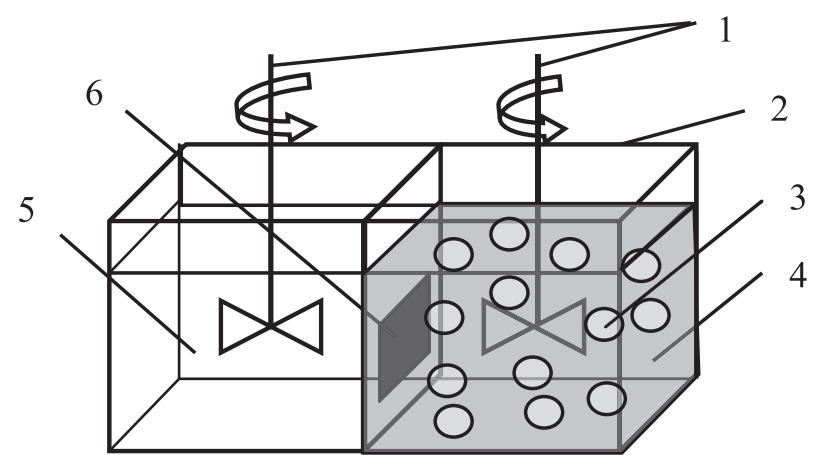

1. Stirrers; 2 . Transport cell; 3. Stripping phase; 4.

Membrane solution; 5 . Feed phase; $3+4$.

Dispersion phase; 6. Membrane

Fig. 1 - Schematic diagram of the DSLM process. 


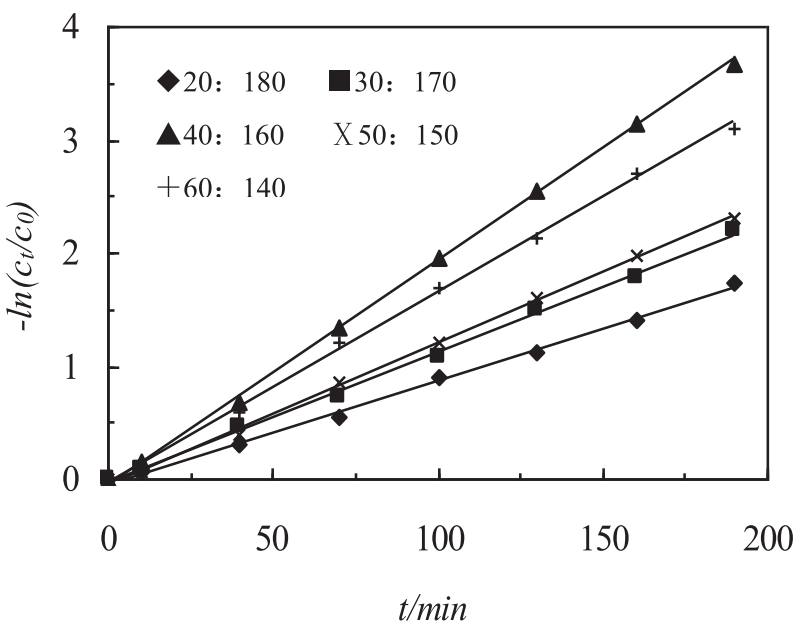

Fig. 2 - Effect of Membrane solution with $\mathrm{HCl}$ volume ratio on the $\mathrm{Pb}$ (II) transport.

stripping rate. The higher the $\mathrm{HCl}$ proportion in dispersion phase, the less stable the generated emulsion, a situation which should adverse to $\mathrm{Pb}$ (II) migration. The smaller proportion shall result in smaller additional stripping area and $\mathrm{Pb}$ (II) migration rate will be reduced accordingly. The volume ratio between the membrane solution and $\mathrm{HCl}$ is one of key factors having influence on $\mathrm{Pb}$ (II) migration rate.

\section{$\mathrm{HCl}$ concentration influence on $\mathrm{Pb}$ (II) transmission}

The feed liquid phase $\mathrm{pH}$ of 6.0 and initial $\mathrm{Pb}$ (II) concentration of $3.0 \times 10^{-4} \mathrm{~mol} / \mathrm{L}$ are selected for the experiment. The volume ratio between the membrane solution and HCI in the stripping phase is $160 / 40$ with the $\mathrm{HCl}$ concentration influence accounts for 1.0, 2.0, 3.0, 4.0 and $5.0 \mathrm{~mol} / \mathrm{L}$ on the $\mathrm{Pb}$ (II) migration. The experiment results are as shown in the following figure (Fig. 3).

The experiment results show that there is a proper linear relation between $\ln \left(c_{t} / c_{0}\right)$ and $t$, and its straight slope varies with the change of $\mathrm{HCl}$ concentration accordingly. When the hydrochloric acid concentration is $4.0 \mathrm{~mol} / \mathrm{L}$ in the stripping

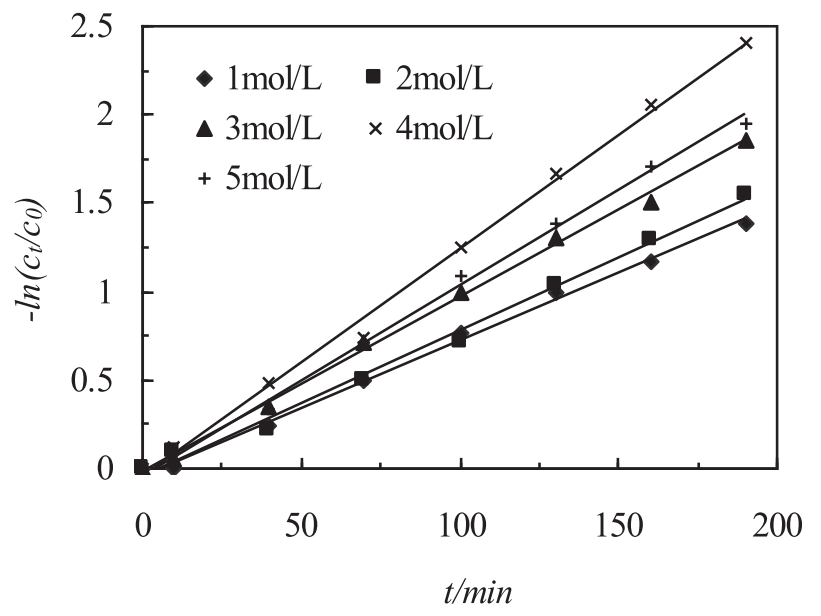

Fig. 3 - Effect of hydrochloric Pbncentrations on the $\mathrm{Pb}$ (II) transport.

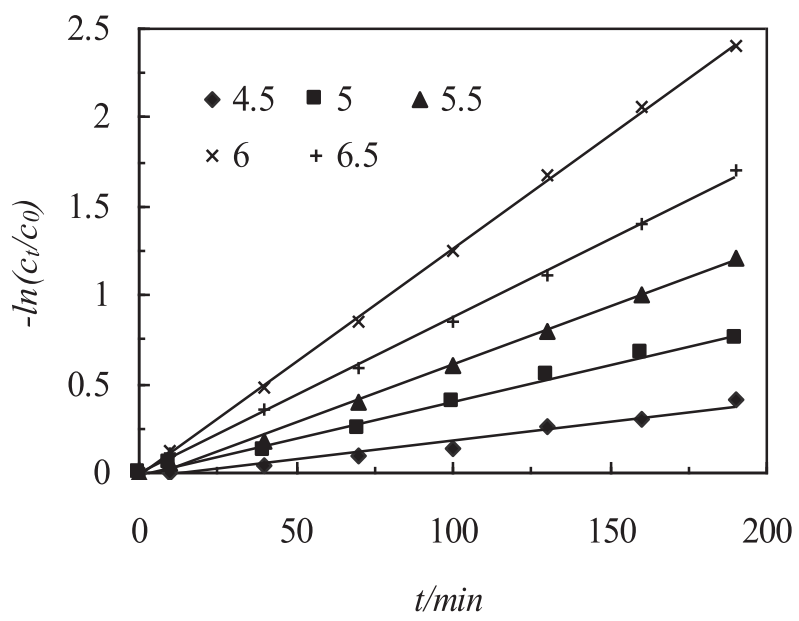

Fig. 4 - Feed phase pH effect on the $\mathrm{Pb}$ (II) transport.

phase (HCI), its straight slope shall increase with the increase in $\mathrm{HCl}$ concentration. If the $\mathrm{HCl}$ concentration keeps increasing, its straight slope shall decrease; the reason for which the higher $\mathrm{HCl}$ concentration in the analytical phase shall results in unstable dispersion liquid. Therefore stripping process cannot keep an effective operation, thus being adverse to the $\mathrm{Pb}$ (II) transmission. When the $\mathrm{HCl}$ concentration is $6.0 \mathrm{~mol} / \mathrm{L}$ in the analytical phase, the $\mathrm{Pb}$ (II) transmission will be favorable.

\section{Feed liquid phase $\mathrm{pH}$ influence on the $\mathrm{Pb}$ (II) transmission}

The $\mathrm{Pb}$ (II) initial concentration of $3.0 \times 10^{-4} \mathrm{~mol} / \mathrm{L}$ in the feed liquid phase is selected for the experiment, the volume ratio is $160 / 40$ between the membrane solution and HCI in stripping phase. $\mathrm{HCl}$ concentration is $4.0 \mathrm{~mol} / \mathrm{L}$ in the stripping phase, the volume ratio between the membrane solution and HCI is $160 / 40$ with the $\mathrm{Pb}$ (II) migration surveyed in case the feed liquid phase $\mathrm{pH}$ accounts for 4.5, 5.0, 5.5, 6.0 and 6.5 respectively.

The experiment results show that when the feed liquid phase $\mathrm{pH}$ is 6.0 , the $\mathrm{Pb}$ (II) migration will be favorable, the reason for which the difference between $\mathrm{H}+$ concentration in the feed liquid phase and stripping phase is the $\mathrm{Pb}$ (II) mass transfer power in the dispersion supported liquid membrane system, hence lower acidity in the feed liquid phase shall be more favorable to the $\mathrm{Pb}$ (II) migration. However, since the stripping agent adopted in the stripping phase is a strong acid, when $\mathrm{pH}$ is higher in this phase, the difference between $\mathrm{H}+$ concentration into two phases accelerates the $\mathrm{H}+$ permeation into membrane phase, which not only strongly impacts on the liquid membrane stability, but also influences $\mathrm{Pb}$ (II) migration rate in the hybrid liquid membrane. Accordingly, the difference in acidity between the feed liquid and stripping dispersion phases is one of the key factors having impact on the $\mathrm{Pb}$ (II) mass transfer rate [23] Fig. 4.

\section{Initial $\mathrm{Pb}$ (II) concentration influence on the $\mathrm{Pb}$ (II) transmission}

The feed liquid phase $\mathrm{pH}$ of 6.0 is selected for experiment, $\mathrm{HCl}$ concentration is $4.0 \mathrm{~mol} / \mathrm{L}$ during the stripping phase, and the 
volume ratio between the membrane solution and $\mathrm{HCl}$ is $160 /$ 40. When the initial $\mathrm{Pb}$ (II) concentration is $1.0 \times 10^{-4} \mathrm{~mol} / \mathrm{L}$, $2.0 \times 10^{-4} \mathrm{~mol} / \mathrm{L}, 2.5 \times 10^{-4} \mathrm{~mol} / \mathrm{L}, 3.0 \times 10^{-4} \mathrm{~mol} / \mathrm{L}$, $4.0 \times 10^{-4} \mathrm{~mol} / \mathrm{L}$, the experimental $\mathrm{Pb}$.(II) migration is as shown in Fig. 5.

Experiment results show that when the initial $\mathrm{Pb}$ (II) concentration is $3.0 \times 10^{-4} \mathrm{~mol} / \mathrm{L}$ in the feed liquid phase, its migration will have a best effect; the reason for which it is observed from Equations (2)-(1) that there is a complex as a result of the chemical reaction between $\mathrm{Pb}$ (II) and $\mathrm{P}_{507}$ at the interface between the feed liquid and membrane phases. When the $\mathrm{Pb}$ (II) concentration is smaller, the equilibrium will move leftward, leading to the reduction in $\mathrm{Pb}$ (II) migration rate. With the increase in $\mathrm{Pb}$ (II) concentration, the equilibrium moves rightward, gradually increasing the $\mathrm{Pb}$ (II) migration rate. But the $\mathrm{Pb}$. (II) migration rate shall also be subject to the carrier concentration and membrane area influence. When the carrier concentration and membrane area are given, the number of $\mathrm{Pb}$ (II) migrating in a unit time will also be definite. $\mathrm{Pb}$ (II) migration rate shall not unboundedly increase with the increase in initial $\mathrm{Pb}$ (II) concentration accordingly. Therefore, initial $\mathrm{Pb}$ (II) concentration shall also be one of the key factors having impact on the $\mathrm{Pb}$ (II) migration rate.

It is obvious that there is a proper linear relation between $-\ln \left(c_{t} / c_{0}\right)$ and the transmission time. Its slope will gradually increase with the increase in initial $\mathrm{Pb}$ (II) concentration [24]. The results show that when $\mathrm{Pb}$ (II) concentration is higher than $3.0 \times 10^{-4} \mathrm{~mol} / \mathrm{L}$, the curve slope will fall and the migration rate will decrease. Therefore, the suitable initial $\mathrm{Pb}$ (II) concentration shall be of about $3.0 \times 10^{-4} \mathrm{~mol} / \mathrm{L}$.

\section{Dynamic analysis}

In the dispersion supported liquid membrane separation system, the feed liquid and dispersion phases are connected by an organic membrane which cannot dissolve in water to make up a three phase system with phases which could not

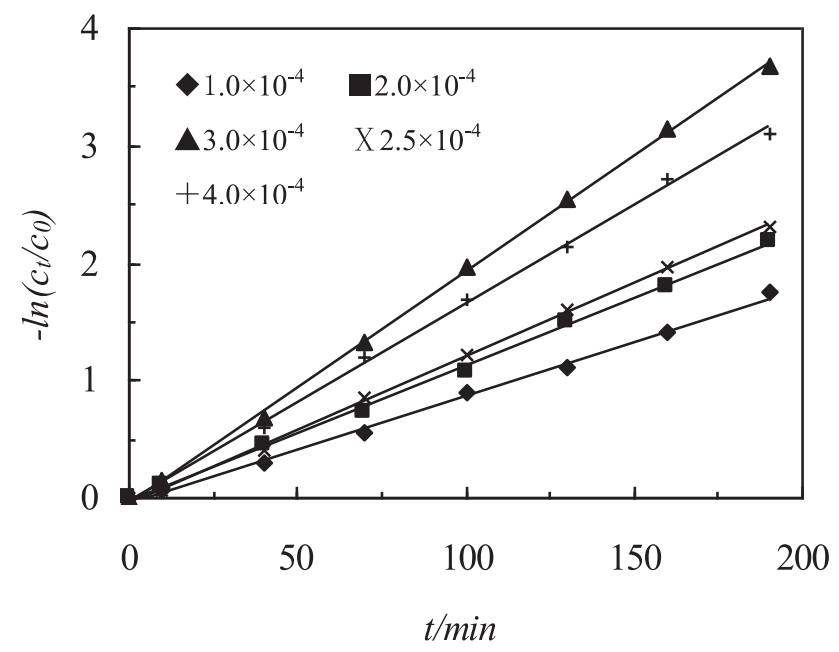

Fig. 5 - Effect of initial $\mathrm{Pb}$ (II) concentrations on the Ni (II) transport.

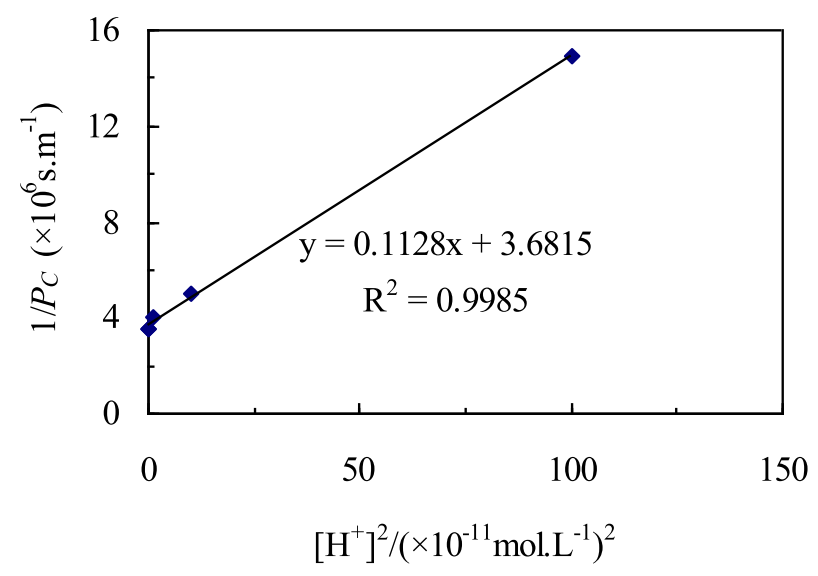

Fig. 6 - $\mathrm{Pb}$ (II) comparison between experimental and theoretical.

dissolve in each or each other [25-27]. These three phases form one body by a chemical reaction at the interfaces to compose a liquid membrane transmission system. It is observed from the above discussion that in addition to the carrier concentration, the feed liquid phase acidity shall be a primary factor having impact on the metal ion given a temperature Fig. 6 .

In order to further describe the metal ion migration process in DSLM, experiments have been made under different $\mathrm{pH}$ values on it. The relation between $\mathrm{Pb}$ (II) $\mathrm{Pc}$ and $[\mathrm{H}+]^{2}$ is as shown in Fig. 5. The relation between the $\mathrm{Pb}$ (II) permeability coefficient and $[\mathrm{H}+]^{2}$ concentration under different feed liquids acidity conditions has been experimented according to the Equation (5). The relation curve between $\mathrm{l} / \mathrm{pc}$ and $[\mathrm{H}+]^{3}$ has been plotted according to Equation (6), and the result shows that there is a proper linear relation $(r=0.9985)$ between $1 / \mathrm{Pc}$ and $[\mathrm{H}+]^{2}$ with its slope and intercept being $0.1128 \times 10^{12}$ and $3.6815 \times 10^{4}$ respectively. Suppose that metal ion migration is primarily in the diffusion form. According to the diffusion coefficient $\mathrm{K}=694 \times 10.10 \mathrm{~m}^{2} \mathrm{~s}^{-1} \mathrm{~Pb}$ (II) extraction complexes in water solution, the diffused layer thickness of $\mathrm{Pb}$ (II) in water phase is $4.23 \times 10^{-5}$ by calculation. According to membrane thickness, the $\mathrm{Pb}$ (II) diffusion coefficient in the membrane phase is $2.24 \times 10^{-13} \mathrm{~m}^{2} \mathrm{~s}^{-1}$ by calculation. The obtained parameters will be substituted in Equation (7) to obtain the $\mathrm{Pb}$ (II) mass transfer dynamic equation in DSLM system as follows:

$$
P_{c}=\frac{1}{3.6815 \times 10^{4}+0.1128 \times 1012[\mathrm{H}+]^{2}}
$$

The theoretical curve obtained according to the equation is as shown in Fig. 5 and this is obvious that the established equation properly tallies with experimental results.

\section{Conclusion}

PC-88A-kerosene-HCl dispersion supported liquid membrane system effects on the $\mathrm{Pb}$ (II) transmission $[28,29]$. In the system, the feed liquid phase $\mathrm{pH}$ value, initial $\mathrm{Pb}$ (II) concentration, volume ratio between the membrane solution, and 
analytical agent and $\mathrm{HCl}$ concentration in analytical phase shall have an impact on the $\mathrm{Pb}$ (II) transmission.

(1) Experiment shows that $\mathrm{P}_{507}$ kerosene- $\mathrm{HCl}$ dispersion supported liquid membrane system has an effect on the $\mathrm{Pb}$ (II) migration. In the system, the feed liquid phase $\mathrm{pH}$ value, initial $\mathrm{Pb}$ (II) concentration, $\mathrm{HCl}$ concentration in the stripping phase, and the volume ratio between membrane solution and $\mathrm{HCl}$ shall have an impact on the $\mathrm{Pb}$ (II) transmission as well.

(2) The results also show that when the feed liquid $\mathrm{pH}$ is 6.0 and initial $\mathrm{Pb}$ (II) concentration is $3.0 \times 10^{-3} \mathrm{~mol} / \mathrm{l}, \mathrm{HCl}$ concentration is $4.0 \mathrm{~mol} / \mathrm{L}$ in the stripping dispersion phase, the volume ratio between the stripping agent and organic phase is 40:160. Therefore, $\mathrm{Pb}$ (II) migration is favorable with $190 \mathrm{~min}$ accounted migration time and the migration rate of up to $95 \%$.

(3) For the dispersion supported liquid membrane system taking $\mathrm{P}_{507}$ as the flow carrier, since a great amount of membrane solution is adopted in the stripping phase, the problem of the flow carrier diminishing to nothing in the supported liquid membrane shall be solved and the $\mathrm{Pb}$ (II) migration rate improved, leading to an enhanced membrane stability and a prolonged membrane service life.

\section{Acknowledgment}

The paper is funded by The National Natural Science Foundation of China (Grant No.:51379219) and Zhejiang province Funds for Distinguished Young Scientists (Grant No.:LR15E090002).

\section{R E F E R E N C E S}

[1] Rivera-Aguilar V, Godínez-Alvarez H, Moreno-Torres R, Rodríguez-Zaragoza S. Soil physico-

chemical properties affecting the distribution of biological soil crusts along an environmental transect at Zapotitlán drylands, Mexico. J Arid Environ 2009;73(11):1023-8.

[2] Yi Lili, Jiao Wentao, Chen Xiaoning, Chen Weiping. An overview of reclaimed water reuse in China. J Environ Sci 2011;23(10):1585-93.

[3] Lu Shibao, Pei Liang, Bai Xiao. Study on method of domestic wastewater treatment through new-type multi-layer artificial wetland. Int J Hydrogen Energy 2015;40(34):11207-14.

[4] Alguaeil FJ, Alonso M. Separation of zinc(II) from cobalt(II) solutions using supported liquid membrane with DP-8R(di(2ethylhexyl)phosphoric acid)as a carrier. Sep Purif Technol 2005;41(2):179-84.

[5] Kumbasar RA, Tutktln O. Separation and concentration of gallium from acidic leach solutions containing various metal ions by emulsion type of liquid membranes using TOPO as mobile carrier. Hydrometallurgy 2004;75(1-4):111-21.

[6] Sarangi K, Das RP. Separation of copper and zinc by supported liquid membrane using TOPS-99 as mobile carrier. Hydrometallurgy 2004;71(3-4):335-42.
[7] Becerra-Castro Cristina, Lopes Ana Rita, Vaz-Moreira Ivone, Silva Elisabete F, Manaia Célia M, Nunes Olga C. Wastewater reuse in irrigation: a microbiological perspective on implications in soil fertility and human and environmental health. Environ Int 2015;75(2):117-35.

[8] Pei L, Yao BH, Zhang CJ. Transport of Tm(III) through dispersion supported liquid membrane containing PC-88A in kerosene as the Carrier. Sep Purifi Technol 2009;65(2):220-7.

[9] Bhattacharyya A, Mohapatra PK, Ansari SA, Raut DR, Manchanda VK. Separation of trivalent actinides from lanthanides using hollow fiber supported liquid membrane containing Cyanex-301 as the carrier. J Membr Sci 2008;312(1-2):1-5.

[10] Zhao JM, Shen XY, Deng FL, Wang FC, Wu Y, Liu HZ. Synergistic extraction and separation of valuable metals from waste cathodic material of lithium ion batteries using Cyanex272 and PC-88A. Sep Purif Technol 2011;78(3):345-51.

[11] Pei L, Yao BH, Wang LM, Zhao N, Liu M. Transport of Tb3+ in dispersion supported liquid membrane system with carrier P507. Chin J Chem 2010;28:839-46.

[12] Neto Artur Pereira, Mansur Marcelo Borges. Transient modeling of zinc extraction with D2EHPA in a Kühni column. Chem Eng Res Des 2013;91(12):2323-32.

[13] Nadimi Hamed, Amirjani Amirmostafa, Fatmehsari Davoud Haghshenas, Firoozi Sadegh, Azadmehr Amirreza. Effect of tartrate ion on extraction behavior of Ni and Co via D2EHPA in sulfate media. Miner Eng 2014;69(12):177-84.

[14] Fortunato Raquel, Afonso Carlos AM, Reis MAM, Crespo João G. Supported liquid membranes using ionic liquids: study of stability and transport mechanisms. J Membr Sci 2004;242:197-209.

[15] Zhang LZ. Fabrication of a lithium chloride solution based composite supported liquid membrane and its moisture permeation analysis. J Membr Sci 2006;276:91-100.

[16] Fortunato Raquel, Afonso Carlos AM, Benavente Juana, Rodriguez-Castellón E, Crespo João G. Stability of supported ionic liquid membranes as studied by X-ray photoelectron spectroscopy. J Membr Sci 2005;256:216-23.

[17] He Dingsheng, Luo Xiaojian, Yang Chunming, Ma Ming, Wan Yan. Study of transport and separation of Zn(II) by a combined supported liquid membrane/strip dispersion containing D2EHPA in kerosene as the carrier. Desalination 2006;194(2):40-51.

[18] Msagati Titus AM, Mamba Bhekie B. Development of supported liquid membrane techniques for the monitoring of trace levels of organic pollutants in waste waters and water purification systems. Phys Chem Earth, Parts A/B/C 2011;36(14-15):1167-77.

[19] Swain B, Jeong J, Lee JC. Separation of Co(II) and Li(I) by supported liquid membrane using Cyanex 272 as mobile carrie. J Membr Sci 2007;297:253-61.

[20] Ghaedi M, Ahmadi F, Soylak M. Preconcentration and transport of Nickel, Copper and Cobalt using solid phase extraction and their determination in some real samples. J Hazard Mater 2007;147:226-31.

[21] El-Said N, Rahman NA, Borai EH. Modification in Purex process using supported liquid membrane separation of Cerium(III) via oxidation to Cerium(IV) from fission products from Nitrate medium by SLM. J Membr Sci 2002;198(1):23-31.

[22] Alpoguz HK, Memon S, Ersoz M, et al. Kinetics of mercury(II) transport through a bulk liquid Membrane containing calix [4] arene derivatives as carrier. Sep Sei Technol 2003;38(7):1649-64.

[23] Ludek Jelinek, Wei Yuezhou, Mikio Kumagai. Adsorption of Ce(IV) anionicnitrato complexes onto anion exchangers and its application for Ce(IV) separation from rare earths(III). J Rare Earths 2006;24(4):385-91. 
[24] Valenzuela F, Fonseca C, Basualto C, Correa O, Tapia C, Sapag J. Removal of copper ions from a waste water by a liquidemulsion membrane method. Min Eng 2005;18(1):33-40.

[25] Guo R, Hu C, Li B, Jiang Z. Pervaporation separation of ethylene glycol/water mixtures through surface crosslinked PVA membranes: coupling effect and separation performance analysis. J Membr Sci 2007;289:191-8.

[26] Frizzell CJ, In Het Panhuis M, Coutinho DH, Balkus KJ, Minett AI, Blau WJ, et al. Reinforcement of macroscopic carbon nanotube structures by polymer intercalation: the role of polymer molecular weight and chain conformation. Phys Rev B-Condens Matter Mater Phys 2005;72:1-8.
[27] Zhang J, Shun CM, Yang GF, Xie F. Separation and enrichment of rare earth elements in phosphorite in Xinhua, Zhijin Guizhou. J Rare Earths 2006;24(1):413-4.

[28] Beltran AB, Nisola GM, Vivas EL, Cho W, Chung WJ. Poly(octylmethylsiloxane)/oleyl alcohol supported liquid membrane for the pervaporative recovery of 1-butanol from aqueous and $\mathrm{ABE}$ model solutions. J Ind Eng Chem 2013;19:182-9.

[29] Yee KF, Ong YT, Mohamed AR, Tan SH. Novel MWCNTbuckypaper polyvinyl alcohol asymmetric membrane for dehydration of etherification reaction mixture: fabrication, characterisation and application. J Membr Sci 2014;453:546-55. 